\title{
MONITORING OF POTABLE WATER QUALITY IN MAKANA LOCAL MUNICIPALITY, SOUTH AFRICA
}

\author{
Thandiswa NQOWANA, C. S. DUBE, R. TANDLICH ${ }^{1}$
}

\begin{abstract}
Monitoring of potable water quality in Makana Local Municipality, South Africa. The aim of this article is to examine the physicochemical and microbial water quality from 3 sampling sites spread across municipal drinking water supply grid in Makana Local Municipality, South Africa. Samples were analysed for the concentrations of faecal coliforms, heterotrophic plate count, the chemical oxygen demand, concentrations of ammonium, phosphate and chlorides. The chloride concentrations ranged from less than 0.01 to $7.60 \pm 0.08 \mathrm{mg} / \mathrm{L}$. At the same time, the ammonium concentrations were found ranging from $0 \mathrm{mg} / \mathrm{L}$ to $1.70 \pm 0.23 \mathrm{mg} / \mathrm{L}$. For the chemical oxygen demand, the measured values ranged from $55 \pm 1$ to $260 \pm 18 \mathrm{mg} / \mathrm{L}$. Finally, the phosphate concentrations were shown to vary between values which were lower than 0.01 $\mathrm{mg} / \mathrm{L}$ up to $1.3 \pm 2.0 \mathrm{mg} / \mathrm{L}$. There were significant differences in the values of all chemical parameters between the various sampling points and the values measured on different sampling occasions (p-value $<0.01$ in all cases, Kruskal-Wallis analysis and $5 \%$ level of significance). A total of 16 drinking water samples were tested for microbial water quality and $75 \%$ of all samples was free of faecal contamination as indicated by the faecal coliform concentration $<0$ colonyforming units per $100 \mathrm{~mL}$. This percentage is lower than the data of $92-100 \%$ of samples free of faecal contamination as published by local government. The discrepancy can be effected by the hygiene habits of the household occupants or from regrowth of organisms in the drinking water distribution system in Makana. Examination of the microbial quality of water led to the discovery of the presence of Vibrio cholera and Aeromonas hydrophila.
\end{abstract}

Keywords: physico-chemical parameters, bacteriological properties, potable water quality, drinking water distribution system

\section{INTRODUCTION}

Access to sufficient water includes both the quality of the water which refers to the absence of adverse substances and bacteria; as well as the quantity of the drinking water supplied (World Health Organization, 2014). In order for the quality of the water to be deemed safe to drink the water has to meet microbial, chemical and physical characteristics specified by World Health Organization (2014). Consumption of potable water of poor quality can lead to waterborne

1 Division of Pharmaceutical Chemistry, Faculty of Pharmacy, Rhodes University, P.O. Box 94, Grahamstown 6140, South Africa, Tel 00-27-46-603-8825, Fax 00-27-46-603-7506, *corresponding author, e-mail: roman.tandlich@gmail.com 
diseases which cause a major burden on human health (World Health Organization, 2014).

This study will be focused on the quality of potable water in Makana Local Municipality (designated as Makana in further text) which is located in the Eastern Cape Province of South Africa (Tandlich et al., 2015). The Eastern Cape Province and the Makana area are prone to droughts and are water-scarce areas (Nhaka, 2012; Tandlich et al., 2015). At the same time, water interruptions are a common occurrence (Nhokodi et al., 2016) and thus water quality problems can be expected to occur. The aim of this article is to examine the physico-chemical and microbial water quality from the various potable water sources in Makana.

\section{METHODS AND MATERIALS}

Three sampling sites were used in this study, namely Tap 1 and 2 in the Eastern part of the Grahamstown area of Makana. These were a communal tap located in the middle of an informal settlement (Tap 1) and a household located inside a house in the same part of town (Tap 2). Tap 3 was located in the western part of the Grahamstown area of Makana and all taps were connected to the municipal drinking water supply.

Water samples were collected on a weekly basis using sterilised (or autoclaved) $1000 \mathrm{ml}$ Schott bottles (Lasec, Port Elizabeth, South Africa), following the general procedure of Tandlich et al. (2014) with several exceptions. The tap was wiped down using baby wipes for sterilisation (Pick'n'Pay, Grahamstown, South Africa). The taps were open and the water was allowed to run for 30 - 45 seconds before each sample was collected by filling the Schott bottle to the brim with the sampled water. The samples were transported to a laboratory in the Faculty of Pharmacy at Rhodes University. The samples were stored at $4{ }^{\circ} \mathrm{C}$ during transport and until analysis.

All analyses for all samples were completed within 12 hours of sampling. All incubations without exception were performed using the Labcon incubator Model FSIM B (Labmark, Johannesburg, RSA), the TS 606/3-I incubator (WTW, Weilheim, Germany), the Labcon low temperature incubator LTIE 10 (Labmark, Johannesburg, RSA); and/or the Heraeus Model FT 420 (Heraeus Kulzer GmbH, Dormagen, Germany). All necessary consumables and chemicals were sterilised using the Model RAU53Bd REX MED autoclave (Hirayama Manufacturing, Tokyo, Japan).

The method used in this study to assess faecal coliform concentrations was the membrane filtration method with incubation on m-FC agar (Merck Pty. Ltd., Port Elizabeth, South Africa). The agar medium was prepared and counting was done according to the manufacturer's instructions and poured into $90 \mathrm{~mm}$ sterile Petri dishes (Spellbound, Port Elizabeth, South Africa). One hundred $\mathrm{mL}$ of each water sample was filtered through a membrane filter with $0.45 \mu \mathrm{m}$ pores (Metricel Membrane Disc filters, Spellbound Labs, Port Elizabeth, South Africa) and the filter was transferred onto the m-FC agar. Each sample was analysed in triplicate. 
The agar was incubated at $44.5 \pm 0.2{ }^{\circ} \mathrm{C}$ for 24 hours and the results were captured in the form of colony-forming units per $100 \mathrm{~mL}$ of water sampled (CFUs/100 mL).

Selected samples were analysed for the concentration of the heterotrophicplate count (HPC). For this, $200 \mu \mathrm{L}$ of water samples were also spread-plated onto R2A agar (Sigma-Aldrich, Johannesburg, South Africa). The agar was again prepared according to the manufacturer's instructions and poured into $90 \mathrm{~mm}$ sterile Petri dishes. The HPC concentrations were determined as growth of white colonies after incubation of the inoculated Petri dishes at $35^{\circ} \mathrm{C}$ for 48 hours.

The results are reported as the colony-forming units per $1 \mathrm{~mL}$ of water sampled (CFUs/mL). After the 48-hour period, 3 loopfulls from the HPOC lawns grown on a single Petri dish was taken and subjected to identification using the API 20E system and the APIWEB database (Apiweb, 2016). Water samples collected were analysed for the concentrations of ammonium, phosphate, chloride and chemical oxygen demand (COD). The $\mathrm{pH}$ values of the samples were measured using the OAKTON Multi-parameter PCTesterTM 35. All analyses were performed using the colorimetric kits which are based on the U.S. EPA/DIN methods which were purchased from Merck Pty. Ltd. (Port Elizabeth, South Africa). The protocols provided by the manufacturer were followed during sample preparation and analysis.

\section{RESULTS AND DISCUSSION}

The $\mathrm{pH}$ values of the water samples were measured in duplicate per sampling site and the values ranged from 6.3-7.9. Results of the chemical analysis are shown in Figure 1 and the results are reported as the arithmetic mean and the error bars represent one standard deviation. The maximum chloride concentration was measured in week 1 of the Tap 1 sampling and it was equal to $7.60 \pm 0.08$ $\mathrm{mg} / \mathrm{L}$. The maximum ammonium concentration was measured in the same tap in week 5 of the study and it was equal to $1.70 \pm 0.23 \mathrm{mg} / \mathrm{L}$. For the COD concentrations, the maximum average value was recorded in Tap 1 and in week 2 of the sampling. The actual value was equal to $260 \pm 18 \mathrm{mg} / \mathrm{L}$. Finally, the maximum phosphate concentration of was measured in Tap 1 and in the sixth week of the sampling programme. The actual value was equal to $1.3 \pm 2.0 \mathrm{mg} / \mathrm{L}$.

The minimum values for $\mathrm{NH} 4+, \mathrm{Cl}-$ and $\mathrm{PO} 43-$ were below $0.01 \mathrm{mg} / \mathrm{L}$. The ammonium and chloride concentrations had minimum values in the samples from Tap 1 and Tap 2 in the first two weeks of the study. The minimum phosphate concentration was recorded in the samples from Tap 3 in week 5 and 6 of the study. At the same time, the minimum COD concentration was equal to $55 \pm 1$ $\mathrm{mg} / \mathrm{L}$ and it was recorded for Tap 2 in week 1 of the sampling in this study. There were significant differences in the values of all parameters between the various sampling points and the values measured on different sampling occasions ( $\mathrm{p}$-value $<0.01$ in all cases, Kruskal-Wallis analysis and $5 \%$ level of significance; Past software package version 2.0, National Museum of Norway, Oslo, Norway). 

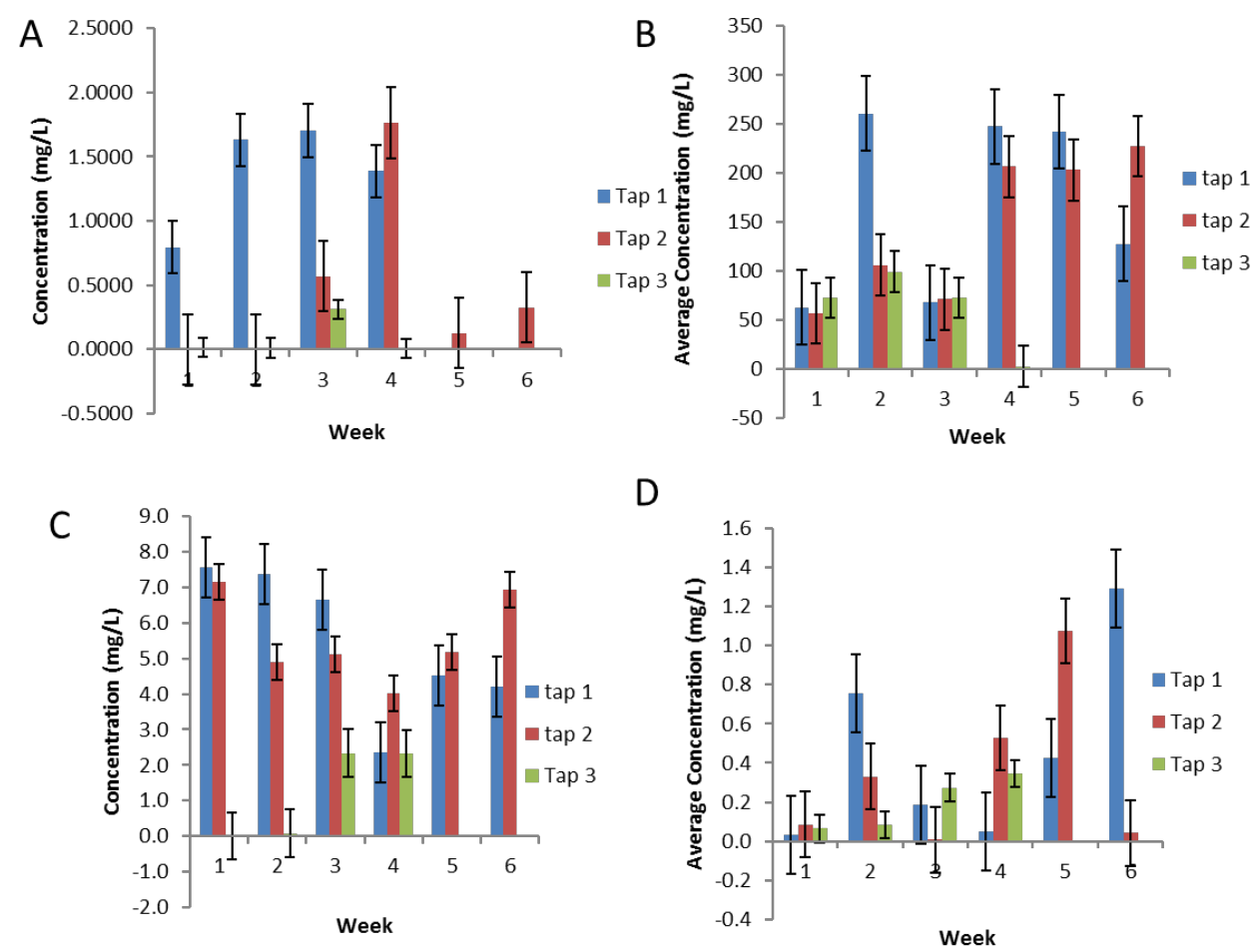

Figure 1: Average concentration of tested chemicals during the sampling of three taps. A: Ammonium concentration. B:
COD Concentration. C: Chloride concentration. D: Phosphate concentration. Chemical analysis was conducted over 6
weeks for taps 1 and 2 and over 4 weeks for tap 3 .

The concentrations of chloride above $250 \mathrm{mg} / \mathrm{L}$ could result in salty taste of the water and thus the consumers could stop using the water (WHO, 2011, page 223). The concentrations observed in this study do not suggest this is the case in Makana. The ammonium concentrations above $1.5 \mathrm{mg} / \mathrm{L}$ could result in salty taste of the water at alkaline $\mathrm{pH}$ and thus the consumers could stop using the water (WHO, 2011, page 223). The concentrations observed in this study do not suggest this is the case in Makana. This is supported by the $\mathrm{pH}$ values ranging from 6.3 to 7.9; and the majority of the water samples contained concentrations below 1.5 mg/L (see Figure 1; (WHO, 2011, page 222). The $\mathrm{pH}$ values were inside the recommended interval of 6.5-8.5 (WHO, 2011, page 226). This indicates that no pipe corrosion of negative effects of $\mathrm{pH}$ on the water distribution infrastructure or the consumers is expected. No negative effects from the concentrations of phosphorus are expected.

Taps 1 and 2 were sampled during six weeks between May and October 2016. The samples were tested for the faecal coliform concentrations and the values were always $<0 \mathrm{CFUs} / 100 \mathrm{~mL}$. Thus the drinking water from these sources complied with the World Health Organisation guidelines for drinking water (WHO, 2011, page 149, Table 7.10). Tap 3 was sampled during 4 weeks between May and 
October 2016. The faecal coliform concentrations ranged from 28 to above 300 CFUs/100 mL. Therefore this municipal drinking water from this source did not meet the requirements for drinking water microbial quality (WHO, 2011, page 149, Table 7.10). Thus a total of 16 drinking water samples were taken during the current study. Twelve samples or $75 \%$ of all samples was free of faecal contamination, which is lower than the data published by Makana Local Government of 92-100 \% (Makana, 2016). The discrepancy can be effected by the hygiene habits of the household occupants or from regrowth of organisms in the drinking water distribution system in Makana. On the other hand, selection of sampling sites might have had an influence on the results, if the treatment breakdown took place.

To get a better understanding of the potential cause, the HPC concentrations were measured in the samples from all three sites. This was done to establish, if the treatment of the drinking water was sufficient throughout the drinking water supply grid. All samples regardless of the tap contained more than $1500 \mathrm{CFUs} / \mathrm{mL}$. Thus the treatment at the Makana municipal water works was insufficient and chlorination must be improved to eliminate the risks to human health upon the potable water consumption. Identification of HPC in water samples was conducted using R2A as a growth media for the bacteria and then re-streaked onto nutrient agar (Merck Pty. Ltd., Port Elizabeth, South Africa). Once nutrient agar produced viable colonies, these were analysed using the API 20E method for identification of the bacterial strains. The strains were identified as Aeromonas hydrophila and Vibrio cholerae (probability of correct identification ranging from 64 to $89 \%$; Apiweb, 2016). These results indicate potential concern about the exposure of Makana population to a potential causative agent of diarrhoeal diseases, namely Aeronomas hydrophila (Tandlich et al., 2016). It can also be responsible for septicaemia and infections in immunocompromised patients (WHO, 2011, page 234). This bacterium's presence in the Makana drinking water supply should be investigated using specific agar media and genetic methods. Vibrio cholerae is indigenous to the Eastern Province and the Makana area; and is not necessarily a concern from the public health point of view.

\section{CONCLUSION}

The results of the study indicate that the water samples from the Makana municipal water supply generally safe for human consumption from a chemical standpoint, but additional treatment is needed to ensure microbial safety of the supply water during distribution to the consumers.

\section{REFERENCES}

1. Apiweb ${ }^{\mathrm{TM}}$. Identification of bacteria using API. [Online]. Available at http://www.slideshare.net/nomanfarrukh3/api-20-e [Accessed 25 October 2016]. 
2. Makana Local Municipality. (2016). Water and waste water quality results for the month of May 2016. Available at: http://www.makana.gov.za/notice-board/waterresults/ (website accessed on 12th December 2016).

3. Ngaka, M. J. (2012). Drought preparedness, impact and response: A case of the Eastern Cape and Free State provinces of South Africa. Jàmbá: Journal of Disaster Risk Studies 4(1): Article \#47, 10 pages, http://dx.doi.org/10.4102/jamba.v4i1.47.

4. Nhokodi, T., Nqowana, T., Collings, D., Tandlich, R., Köhly, N. (2016). Civic engagement and environmental sustainability in teaching and learning at a higher education institution in South Africa. Acta Technologica Dubnicae 6(3): in press.

5. Tandlich, R., Ncube, M., Khamanga, S. M. M., Zuma, B. M. (2016). A case study on the health risks related to flood disasters in South Africa. Journal of Disaster Research 11(4): 732-741.

6. Tandlich, R., Luyt, C. D., Irwin, B., Thinyane, H., Köhly, N. (2015). Nongovernmental information sources about microbial drinking water quality in South Africa. Published in the peer-reviewed conference proceedings from the 15th SGEM GeoConference on Water Resources. Forest, Marine and Ocean Ecosystems, Volume 2: ecology, economics, education and legislation conference proceedings- ecology and environmental protection environmental legislation, multilateral relations and funding opportunities, Albena, Bulgaria from 18th until 24th June 2015, published by STEF92 technology, pp. 761-768, (ISBN 978-6197105-40-7).

7. Tandlich, R., Luyt, C. D., Ngqwala, N. P. (2014). A community-based rainwater monitoring and treatment programme in Grahamstown, South Africa. Journal of Hydrocarbons, Mines and Environmental Research 5(1): 46-51.

8. World Health Organization (WHO, 2014). Microbial Aspects. Available at: http://www.who.int/water_sanitation_health/dwq/GDW7rev1and2.pdf?ua=1 (website accessed on 12th December 2016). .

9. World Health Organisation (WHO, 2011). Guidelines for drinking water quality, 4th Edition, WHO Press, Geneva, Switzerland. 